\title{
INNOVATION PROCESS - TOWARDS ACHIEVING ORGANIZATIONAL AMBIDEXTERITY: RESEARCH RESULTS
}

\author{
Pawel Mielcarek ${ }^{1}$
}

Received: December 8, 2018 / Revised: January 22, 2019/ Accepted: March 12, 2019

(C) Association of Economists and Managers of the Balkans, 2019

\begin{abstract}
Innovation process is one of activities that have strategic importance for long term success of company due to possibility to develop and change key competencies, capabilities and competitive advantages. However one of crucial issues of managing organization is achieving balance between securing present revenue streams and ability of creating new value for customers. Therefore the main goal of this paper is to recognize the relation between different configurations of innovation process and achieved results of organization's ambidexterity level. These issues were subject of survey covering 400 medium and large size Polish entities and period of 2015-2017. Most important finding is that there is positive correlation between implementation level of innovation process and achieved ambidexterity level. This paper is addressed to researchers as well for practitioners of management, especially $R+D$ managers, COO and CEO.
\end{abstract}

Keywords: Innovation process, ambidexterity, value capture, value creation, innovation

\section{JEL Classification O31 $\cdot 032 \cdot \mathbf{L} 20 \cdot \mathrm{M} 10$}

This paper was presented at the Second International Scientific Conference on IT, Tourism, Economics, Management and Agriculture - ITEMA 2018 - November 8, 2018, Graz, Austria, www.itema-conference.com

Paweł Mielcarek

pawel.mielcarek@ue.poznan.pl

1 Poznan University of Business and Economics, al. Niepodległości 10, 61-875 Poznań, Poland 


\section{INTRODUCTION}

One of the important activities that bring positive results for the company in the long run is innovation, which allows developing new approaches to increase competitiveness and improve the company's performance. The new economy does not mean undermining and rejecting short term results as the basic criteria of enterprise's operation. Instead it points to a fundamental change in the manner in which these postulates are achieved. It is necessary to reorient to the capabilities that support a quick and flexible response to market impulses. In addition, it is postulated to adopt the concept of a business model that supports the creation of added value resulting from the adaptation of different values and focus on the development of intangible assets and the increase in return on investment (Davenport, Leibold, \& Voelpel, 2005).

In this perspective, the functioning of an enterprise can be considered in the context of one of the key management paradoxes. On the one hand, there is a need to develop, implement innovations and adapt to the dynamically changing environment, whereas these activities are usually characterized by a long-term perspective and are burdened with a high level of risk (Karpacz, 2015). On the other hand, through self-organization of the system, enterprises aim at stabilization, which is induced by the need to achieve the effectiveness of the process of creating economic value. In this sense aim of the organization is to ensure survival in the short and medium term by maintaining current income streams (Baden-Fuller \& Volberda, 1997).

The concept that assumes the balancing of those areas: exploration focusing on value creation and exploitation directed at value capture is ambidexterity. The term was first used by R. Duncan for organizations with dual structures that allow simultaneous implementation of activities with different time horizons and thus require the use of different managerial abilities (Duncan, 1976). J. March created the theoretical foundations for the ambidexterity of the organization pointed to the necessity of simultaneous use of two key activities: exploration and exploitation, stressing that achieving balance between these operations determines the well-being of the organizational system (March, 1991).

He considered exploration as a search for new development opportunities through the use of research, changes, experiments, discoveries as well as flexibility, innovation and risk taking (March, 1991). Exploration requires investments associated with searching for new solutions and testing them, while the return on developed and commercialized innovations is postponed.

On the other hand, exploitation is aimed at maintaining current efficiency, control, improvement, implementation and operationalization, increasing certainty and reducing diversity, and in a broader sense at generating profits in the short term (March, 1991). It is focused on maintaining a competitive advantage on the market in terms of existing products and technologies by reducing costs and achieving economies of scale (Zakrzewska-Bielawska, 2018).

Main goal of this paper is to recognize the relation between different configurations of innovation process and achieved results of organization's ambidexterity. To ensure this goal, an author's model of innovation process was proposed. 


\section{RESEARCH METHOD - CONCEPTUALIZATION AND OPERATIONALIZATION OF VARIABLES}

The subjective scope of empirical research is 400 medium-sized and large enterprises operating in the territory of the Republic of Poland. The time range covers the years 2015-2017. A stratified random-controlled sampling was used in the studies, with the layers representing the size of the enterprise and the business section according to the division of REGON register (as at 31/12/2017) provided by the Central Statistical Office of Poland (http://bip.stat.gov.pl/).

Both key variables analyzed in this paper need to be conceptualized and operationalized. First of them is innovation process that is based on the following assumptions:

1. The innovation process is embedded in the company's strategy, and by cascading objectives, it includes further levels of the organization's functioning, i.e. the strategic, the regulatory and operational dimension. The proposed process enables implementation of both the open innovation and closed innovation model (Gassmann \& Enkel, 2004; Lichtenthaler \& Lichtenthaler, 2009).

2. The four stages of innovation process management are distinguished: 1) analysis and planning, referring to determining the scope and directions of organization development based on innovative activity, 2) implementation describing the introduction of activities in the organization and their implementation, 3) control including a comparison of the obtained results with planned goals and 4) improvement and standardization based on the construction of the feedback flow obtained from the control phase. Model of innovation process consists of 23 actions (see figure 1).

3. With respect to the regulatory level, the activities constituting the shaping of the innovation management system have been distinguished. The proposal indicates both elements directly resulting from the assumptions of open innovation as knowledge management, but also a number of other activities, such as the development of procedures and motivation system, shaping the organizational culture and styles of management, or competency management. The indicated areas to a large extent determine the ability of the organization to adapt to changes and create innovations. In addition, these elements interact with each other and are related to complex relationships, which is why they are presented in the figure in a single block without indicating specific relationships.

4. At the operational level, the innovation process has been supplemented with the portfolio management issues, including the need to measure the effectiveness of innovative projects. The course of individual innovation projects may consist of eight activities, however their configuration differs depending on the specificity of the implementation of a given project. For example, a resource development stage may not occur or the innovation can be created only by the organization, so without the co-creation stage and intended for sale on the new market, i.e. other variants are omitted. Therefore, no links were identified between these activities, grouping them into one block.

5. Another assumption under the presented concept is the continuous improvement of the innovation process, whose changes affect the reconfiguration of the business model. Improvement of the innovation process refers to two areas. First, the regulatory layer, and therefore the innovation management system. Secondly, it provides an information feed for the process, the choice of the direction of the organization's development and, subsequently, changes in the business model.

6. The last assumption is possibility of implementing each of process's actions with different level of intensity. The degree of intensity of the implementation of the innovation process includes three levels: lack of implementation was rated as 0 , partial implementation - rated 
as 1 , and performance in a comprehensive manner - rated as 2. In particular, in the longterm perspective, a gradual decrease in the intensity of implementation of activities belonging to the analysis and planning stage for the increase of intensity of activities related to improvement of the innovation process will be observed. This cycle is repeated when changes occur in the business model of the organization, which result in the need to readapt the process of innovation.

Although the presented concept includes as many as twenty-three actions it can be still developed. However, assuming maintaining the applicability value, one should strive to ensure transparency and universality of the formulated concept, which limits the possibilities of model extension.

Second variable is ambidexterity of the organization, that is determined by four areas: companys goal, products, market and competitive advantage for both exploration and exploitation activities (see table 2). There are two questions regarding each individual ambidexterity measurements (Zakrzewska-Bielawska, 2018). Then, each of the measure was valued on the basis of the 1-7 scale. Next, the means for the measurements of exploration and exploitation were calculated. Finally level of ambidexterity is a sum of exploration and exploitation averages, which means that it can achieve values from 2 to 14 .

Table 1. Operationalization of ambidexterity of organization. Source: own preparation.

\begin{tabular}{|c|c|c|}
\hline $\begin{array}{l}\text { Operational } \\
\text { construct }\end{array}$ & \multicolumn{2}{|c|}{ Measurement of the construct } \\
\hline \multirow{8}{*}{$\begin{array}{l}\text { Exploration } \\
\text { activities }\end{array}$} & \multirow[t]{2}{*}{ company`s goal } & $\begin{array}{l}\text { The company's development was made from the perspective of } \\
\text { long-term profits }\end{array}$ \\
\hline & & New market opportunities were used \\
\hline & \multirow{2}{*}{ product } & New products were created \\
\hline & & The range of products has been expanded \\
\hline & \multirow[b]{2}{*}{ market } & Entry into new markets has been made \\
\hline & & $\begin{array}{l}\text { New, unique utility values were offered to clients } \\
\text { competitive advantage }\end{array}$ \\
\hline & \multirow{2}{*}{$\begin{array}{l}\text { competitive } \\
\text { advantage }\end{array}$} & The company`s competences have been developed \\
\hline & & A new competitive advantage was created \\
\hline \multirow{8}{*}{$\begin{array}{l}\text { Exploitation } \\
\text { activities }\end{array}$} & \multirow[b]{2}{*}{ company`s goal } & Short-term profits have been hedged and generated \\
\hline & & $\begin{array}{l}\text { Continuous improvement was carried out and efficiency gains } \\
\text { were achieved }\end{array}$ \\
\hline & \multirow{2}{*}{ product } & The existing products have been improved \\
\hline & & Production costs have been reduced \\
\hline & \multirow[b]{2}{*}{ market } & Increased economies of scale in existing markets \\
\hline & & $\begin{array}{l}\text { Satisfaction of existing customers in a systematic manner was } \\
\text { investigated }\end{array}$ \\
\hline & \multirow{2}{*}{$\begin{array}{l}\text { competitive } \\
\text { advantage }\end{array}$} & The existing competences have been improved \\
\hline & & The current competitive advantage was protected and maintained \\
\hline
\end{tabular}




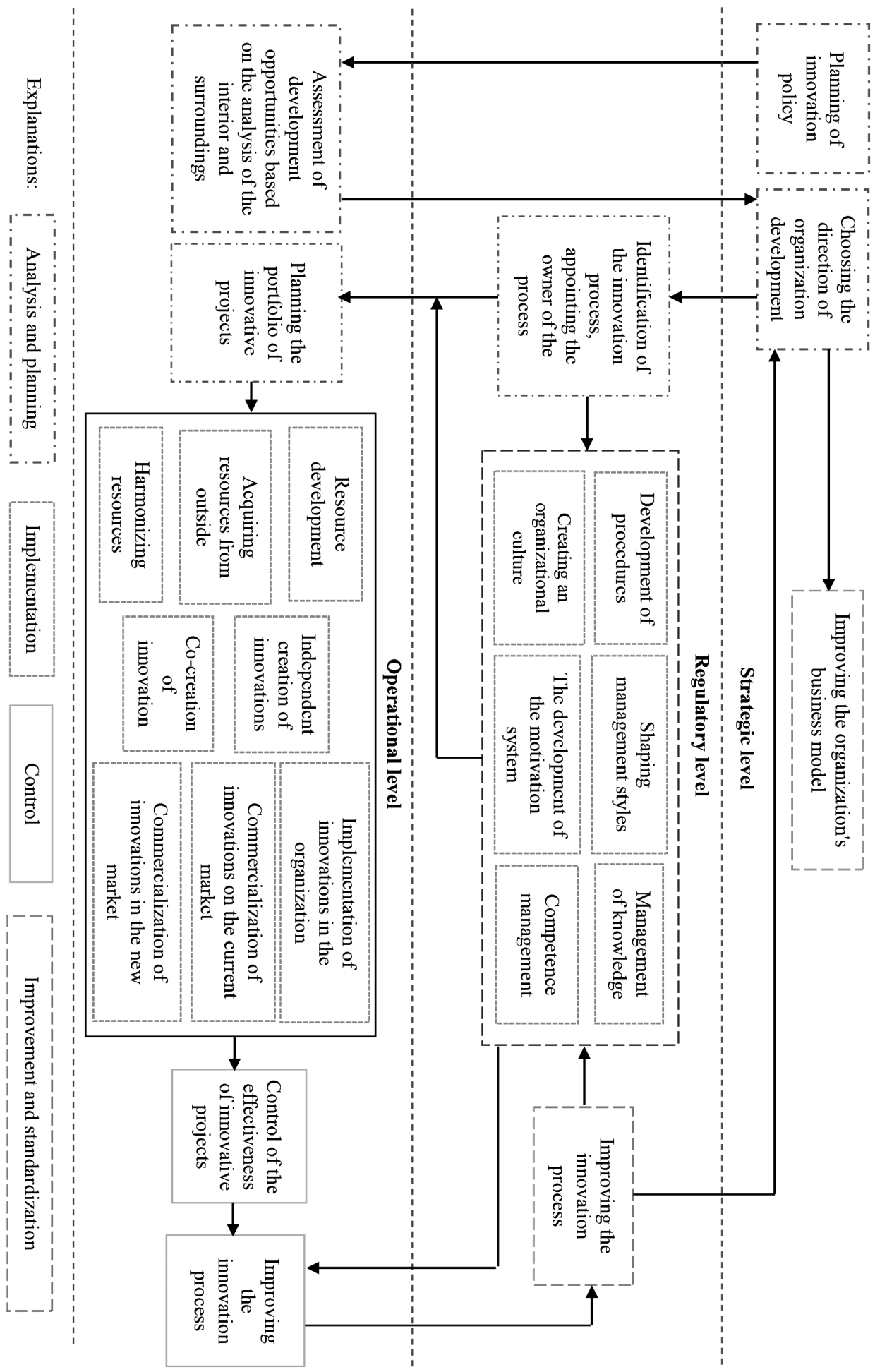

Figure 1. Innovation process model. Source: own preparation. 


\section{RESEARCH RESULTS}

In the presented research group of enterprises the correlation coefficient between intensity of innovation process and level of organization's ambidexterity is 0,565 , which can be interpreted as moderate/strong relation. This means that companies characterized by higher intensity of innovation process achieve higher level of ambidexterity.

The average level of exploration is 4.26, while exploitation is 4.51 within the scale from 1 to 7 . Both results exceed the average and have relatively similar values. Overall ambidexterity level of researched enterprises was 8.76 (in scale from 2 to 14), which is moderate result. However it is based on two balanced and complementary areas of operation.

In the case of exploration, the most important measure is achieving the company's goals (4.57), with the market having the lowest score (3.76). Such a result can be interpreted as the occurrence of an inside-out approach in the conduct of exploration activities, appreciation of the planning approach and the importance of internal conditions in the development of medium and large size Polish enterprises.

In implementation of exploitation, a slightly different result is achieved. The most important measurement is to maintain the current competitive advantage (4.92) with the lowest result for the market (4.16). The dominant role of maintaining a competitive advantage can be interpreted as a strategy focused on securing current streams of income and at the same time boosting profit in a short period of time, which allows financing investments in innovation and ensuring ongoing operations.

The average intensity of implementation of innovation process for medium and large size Polish enterprises is 0.80 and is noticeably lower than the results obtained by enterprises characterized by a high level of exploration (1.16), exploitation (1.00) and ambidextrous (1.20) (see table 2).

Among the distinguished stages of the innovation process, the most emphasis is on analyzing and planning (1.15) and the smallest on improvement and standardization (0.96), while phases implementation and control achieve similar results, 1.02 and 1.03 , respectively.

In relation to specific activities that make up the innovation process, the highest average level of intensity is characterized by the planning of innovation policy (1.25) and the lowest commercialization of innovation in the new market (0.37). It is worth emphasizing that especially in the case of activities related to the commercialization of innovations, both on current and new markets, enterprises that achieved high levels of ambidexterity were characterized by more than twice the level of intensity of implementation of these measures for all enterprises undertaking the innovation process.

The predominance of the intensity of implementation of exploration activities (1.16) in relation to exploitation activities (1.00) is the expected result in relation to the specificity of the innovation process. However, it is interesting to note that enterprises that have achieved a high level of ambidexterity are characterized by a much higher intensity of the innovation process (1.20) compared to enterprises focusing either on exploration activities or exploitation. This may mean that entities wishing to provide complementary support both in the area of value creation and the capture of values should strive to achieve a high level of intensity of the innovation process implementation. 
Table 2. Intensity of innovation process activities according to ambidexterity level for medium and large Polish enterprises in 2015-2017, $\mathrm{n}=400$.

Source: own preparation.

\begin{tabular}{|c|c|c|c|c|}
\hline Activities of the innovation process & $\begin{array}{c}\text { Medium and } \\
\text { large Polish } \\
\text { enterprises } \\
n=400\end{array}$ & $\begin{array}{c}\text { High level of } \\
\text { exploration } \\
(5-7), n=111\end{array}$ & $\begin{array}{c}\text { High level of } \\
\text { exploitation } \\
(5-7), n=132\end{array}$ & $\begin{array}{c}\text { High level of } \\
\text { ambidexterity } \\
(11-14), n=76\end{array}$ \\
\hline
\end{tabular}

\section{Analysis and planning}

\begin{tabular}{|l|c|c|c|c|}
\hline Planning of innovation policy & 1,25 & 1,28 & 1,17 & 1,29 \\
\hline $\begin{array}{l}\text { Assessment of development } \\
\text { opportunities based on the analysis of } \\
\text { the interior and surroundings }\end{array}$ & 1,16 & 1,19 & 1,08 & 1,11 \\
\hline $\begin{array}{l}\text { Choosing the direction of organization } \\
\text { development }\end{array}$ & 1,22 & 1,29 & 1,18 & 1,30 \\
\hline $\begin{array}{l}\text { Identification of the innovation process, } \\
\text { appointing the owner of the process }\end{array}$ & 0,95 & 1,17 & 0,95 & 1,13 \\
\hline
\end{tabular}

Implementation

\begin{tabular}{|l|c|c|c|c|}
\hline Competence management & 0,85 & 1,33 & 1,20 & 1,42 \\
\hline Development of procedures & 0,89 & 1,32 & 1,20 & 1,32 \\
\hline Shaping the styles of targeting & 0,77 & 1,15 & 1,11 & 1,22 \\
\hline Management of knowledge & 0,93 & 1,40 & 1,25 & 1,46 \\
\hline Creating an organizational culture & 0,80 & 1,23 & 1,10 & 1,29 \\
\hline $\begin{array}{l}\text { The development of the motivation } \\
\text { system }\end{array}$ & 0,77 & 1,26 & 1,14 & 1,32 \\
\hline $\begin{array}{l}\text { Planning the portfolio of innovative } \\
\text { projects }\end{array}$ & 0,70 & 1,31 & 1,06 & 1,26 \\
\hline Resource development & 0,62 & 0,98 & 0,86 & 1,24 \\
\hline Acquiring resources from outside & 0,70 & 1,21 & 1,03 & 0,96 \\
\hline Harmonizing resources & 0,61 & 1,00 & 0,89 & 1,07 \\
\hline Independent creation of innovations & 0,67 & 1,19 & 1,02 & 1,25 \\
\hline Co-creation of innovation & 0,57 & 1,03 & 0,89 & 1,01 \\
\hline $\begin{array}{l}\text { Implementation of innovations in the } \\
\text { organization }\end{array}$ & 0,59 & 0,97 & 0,89 & 1,05 \\
\hline $\begin{array}{l}\text { Commercialization of innovations on } \\
\text { the current market }\end{array}$ & 0,49 & 0,93 & 0,81 & 1,00 \\
\hline $\begin{array}{l}\text { Commercialization of innovations in } \\
\text { the new market }\end{array}$ & 0,37 & 0,75 & 0,66 & 0,82 \\
\hline
\end{tabular}

\section{Control}

\begin{tabular}{|l|c|c|c|c|}
\hline $\begin{array}{l}\text { Control of the effectiveness of } \\
\text { innovative projects }\end{array}$ & 0,75 & 1,24 & 1,12 & 1,37 \\
\hline $\begin{array}{l}\text { Control of the effectiveness of the } \\
\text { innovation process }\end{array}$ & 0,94 & 1,08 & 0,89 & 1,20 \\
\hline
\end{tabular}

\section{Improvement and standardization}

\begin{tabular}{|l|c|c|c|c|}
\hline Improving the innovation process & 0,88 & 1,10 & 0,48 & 1,21 \\
\hline $\begin{array}{l}\text { Improving the organization's business } \\
\text { model }\end{array}$ & 1,03 & 1,20 & 1,08 & 1,22 \\
\hline Average & $\mathbf{0 , 8 0}$ & $\mathbf{1 , 1 6}$ & $\mathbf{1 , 0 0}$ & $\mathbf{1 , 2 0}$ \\
\hline
\end{tabular}




\section{CONCLUSIONS}

The main goal of this paper is to recognize the relation between different configurations of innovation process and achieved results of organization's ambidexterity. In order to verify those dependency an author's model of innovation process consisting of 23 activities was presented. The correlation coefficient between intensity of innovation process activities and organization's ambidexterity level is 0,565 , which can be interpreted as moderate/strong relation. Based on presented research results following recommendations for researchers and managers were proposed.

It is recommended to strive for achieving internal coherence of the innovation process, which refers to two areas. Firstly, to align levels of intensity of implementation between particular stages of the process (analysis \& planning, implementation, control, etc.). Secondly, the increase in coherence between the intensity of the innovation process, including closing the gap between operational and regulatory and strategic levels.

It is postulated to raise the average intensity of the innovation process, because it is related with increasing ambidexterity level. So, in order to achieve a high level of ambidexterity, it is necessary to concentrate on the implementation of: control of the effectiveness of innovative projects (the difference between all enterprises realizing the innovation process and enterprises that have reached high level of ambidexterity is 0.62 ), resource development (the gap is 0.62 ), independent creation of innovations (the difference is 0.58 ) and competence management (the gap is 0.57 ).

\section{ACKNOWLEDGEMENTS}

This text was created using funds from a scientific grant awarded by the National Science Center, Poland as part of the project with the number UMO-2016/21 / D / HS4 / 00696 entitled "Improving the processes of open innovation and strategic renewal of the enterprise". (Project leader dr Paweł Mielcarek)

\section{REFERENCES}

Baden-Fuller, C., \& Volberda, H. (1997). Strategic renewal: How large complex organizations prepare for the future, International Studies of Management \& Organization, 27(2), 95-120.

Davenport, T., Leibold, M., \& Voelpel, S. (2005). Strategic Management in the Innovation Economy. Strategic Approaches and Tools for Dynamic Innovation Capabilities. Erlangen: Publics Corporate Publishing.

Duncan, R. (1976). The ambidextrous organization, designing dual structures for innovation, (In.) R. Kilman, \& L. Pondy (Ed.) "The Management of Organizational Design". New York: North Holland.

Gassmann, O., \& Enkel, E. (2004). Towards a theory of open innovation: three core process archetypes. Proceedings of The R\&D Management Conference, Lisbon, Portugal, July, 6-9.

Karpacz, J., (2015). Spojrzenie na odnowę strategiczną z punktu widzenia długowieczności organizacji, Management Forum, 3(1), 84-90.

Lichtenthaler, U., \& Lichtenthaler, E. (2009). A capability-based framework for open innovation: complementing absorptive capacity. Journal of Management Studies, 46(8),1315-1338.

March, J. (1991). Exploration and Exploitation in Organizational Learning. Organization Science, 2(1), 71-86.

Zakrzewska-Bielawska, A. (2018). Strategie rozwoju przedsiębiorstw. Nowe spojrzenie. Warszawa: PWE. 